\title{
1 ARRANJO PRODUTIVO LOCAL E DESENVOLVIMENTO SUSTENTÁVEL: UMA RELAÇÃO SINÉRGICA NO MUNICÍPIO DE MARCO (CE)
}

RAFAELLA ALVES MEDEIROS ALVARENGA

Mestra em Administração pelo Programa de Pós-Graduação em Administração da Universidade de Fortaleza (Unifor). Avenida Washington Soares, 1.321, bloco P, sala 17, Edson Queiroz, Fortaleza - CE - Brasil - CEP 6081 1-905

E-mail: rafaella.alves.medeiros@gmail.com

FÁTIMA REGINA NEY MATOS

Doutora em Administração pelo Programa de Pós-Graduação em Administração da Universidade Federal de Pernambuco (UFPE).

Professora do Programa de Pós-Graduação em Administração da Universidade de Fortaleza (Unifor). Avenida Washington Soares, 1.321, bloco P, sala 17, Edson Queiroz, Fortaleza - CE - Brasil - CEP 6081 1-905 E-mail: fneymatos@unifor.br

\section{DIEGO DE QUEIROZ MACHADO}

Doutorando do Programa de Pós-Graduação em Administração da Universidade de Fortaleza (Unifor). Avenida Washington Soares, 1.321, bloco P, sala 17, Edson Queiroz, Fortaleza - CE - Brasil - CEP 6081 1-905

E-mail: diegoqueirozm@yahoo.com.br

\section{MICHELLLE DO CARMO SOBREIRA}

Mestranda do Programa de Pós-Graduação em Administração da Universidade de Fortaleza (Unifor). Avenida Washington Soares, 1.321, bloco P, sala 17, Edson Queiroz, Fortaleza - CE - Brasil - CEP 6081 1-905

E-mail: michellesobreira@gmail.com

\section{LORENA BEZERRA DE SOUZA MATOS}

Mestra em Administração de Empresas pelo Curso de Mestrado Acadêmico em Administração da Universidade Estadual do Ceará (Uece).

Bolsista do Programa de Ecoindustrialismo do Sesi-Senai/CE. Rua Tibúrcio Cavalcante, 2.331, Dionísio Torres, Fortaleza - CE - Brasil - CEP 60125-101 E-mail: lorenabmatos@gmail.com

Os autores agradecem ao Conselho Nacional de Desenvolvimento Científico e Tecnológico (CNPq) o financiamento da pesquisa.

Este artigo pode ser copiado, distribuído, exibido, transmitido ou adaptado desde que citados, de forma clara e explícita, o nome da revista, a edição, o ano e as páginas nas quais o artigo foi publicado originalmente, mas sem sugerir que a RAM endosse a reutilização do artigo. Esse termo de licenciamento deve ser explicitado para os casos de reutilização ou distribuição para terceiros. Não é permitido o uso para fins comerciais. 


\section{RESUMO}

Com a evolução do próprio conceito de desenvolvimento, mediante o fortalecimento do paradigma da sustentabilidade, torna-se necessária uma evolução das discussões em torno dos arranjos produtivos locais (APLs) que incorpore ponderações acerca de tais dimensões. Dessa forma, este estudo tem como objetivo geral analisar a ocorrência de práticas de desenvolvimento sustentável, com base no modelo triple bottom line, em um arranjo produtivo local. Para tanto, escolheu-se como campo empírico de estudo um APL de móveis localizado no município de Marco, no Estado do Ceará. Sua escolha para este trabalho se deveu tanto às características desse tipo de atividade, que, por depender da extração e utilização de recursos naturais, principalmente a madeira, apresenta grande relação com questões da dimensão ambiental da sustentabilidade, quanto ao reconhecimento do forte desempenho econômico do APL de Marco, que fez com que a cidade fosse reconhecida como um dos maiores polos moveleiros do Norte e Nordeste do país. Procurou-se identificar demonstrações econômicas (profit), sociais (people) e ambientais (planet), bem como verificar a ocorrência de sinergia na relação arranjo produtivo e desenvolvimento sustentável. Na revisão da literatura, foram construídos tópicos sobre a abordagem teórica de arranjos produtivos locais, o papel do empresário político ou empresário coletivo, o desenvolvimento sustentável e o modelo triple bottom line. A metodologia fundamentou-se em abordagem qualitativa, cujas técnicas de coleta foram a entrevista semiestruturada, a observação e um corpus documental. Foram escolhidos intencionalmente e por acessibilidade seis empreendedores. Pode-se concluir que, com base no modelo triple bottom line, estão presentes algumas características de desenvolvimento sustentável, principalmente relacionadas às dimensões ambiental (planet) e econômica (profit). A dimensão social (people) ainda precisa ser aperfeiçoada, o que pode acontecer pela influência do agente sinérgico ou empresário político. Em suma, este estudo contribui para o entendimento acerca das relações entre as diversas dimensões do desenvolvimento sustentável e as práticas observadas no contexto dos APLs. 


\section{PALAVRAS-CHAVE}

Desenvolvimento sustentável; Arranjo produtivo local; Triple bottom line; Relação sinérgica; Polo moveleiro.

\section{INTRODUÇÃO}

As expressões globalização dos mercados, globalização da economia e nova divisão internacional do trabalho são representações da realidade atual. Observa-se, nas duas últimas décadas, um debate acirrado sobre as possíveis causas da exclusão social e estratégias de desenvolvimento. Ocorre que, historicamente, o Estado e os mecanismos de mercado não se mostraram capazes de executar um plano de desenvolvimento sustentável e socialmente justo. As transformações contempladas no tocante à fragmentação territorial e à exclusão social advindas da globalização da economia fizeram ressurgir as identidades culturais e políticas tanto no nível regional como no âmbito local (JAMES et al., I997).

A globalização da economia provocou alterações que se refletem nos ambientes urbanos e rurais. Como consequência da dinâmica econômica global, não se podem estabelecer planos que não possam ser mudados no curto prazo. Assim, o que norteia em termos de decisão pública, privada, política e econômica sob o prisma do desenvolvimento é visto no nível global integrado com a especificidade local (MARTINELLI; JOYAL, 2004).

Essas transformações e o desenvolvimento de novos tipos flexíveis de organização da produção ocasionaram o fim do modelo consagrado pela produção em massa intitulado fordista. Para Baptista (2002) e Keller (2008), o interesse nos distritos industriais surgiu em meados da década de I980, tanto no âmbito acadêmico como no político, em que se desenvolveu um novo modelo de sistema produtivo, a chamada "especialização flexível", tendo como seu maior exemplo a Terceira Itália.

A identificação e a relevância dos distritos industriais impulsionaram os estudos acerca dos arranjos produtivos locais, cujo precursor foi o economista Alfred Marshall (i985), que observou que algumas regiões possuíam concentrada aglomeração de empresas de um mesmo setor e constatou a importância de fatores locacionais como tradição, relacionando condições físicas, o solo, o clima, a facilidade de encontrar matéria-prima, fácil acesso, boa saída da produção etc.

Com base no conceito marshalliano, Sengenberger e Pike (I999, p. I02) identificaram, nos distritos industriais, as seguintes características: 
- RAFAELLA ALVES M. ALVARENGA • FÁTIMA REGINA NEY MATOS • DIEGO DE QUEIROZ MACHADO • - MICHELLE DO CARMO SOBREIRA • LORENA BEZERRA DE SOUZA MATOS •

Organização social e econômica baseada em pequenas empresas; formação de redes de empresas; mesmo setor industrial; delimitação geográfica; difusão de idéias e inovações técnicas; coesão social e consciência coletiva; facilidade e velocidade das transações entre empresas; disposição das empresas para co-operação e dinamismo empresarial.

Nesse sentido, pode-se inferir que as características apontadas por Sengenberger e Pike (I999) possibilitam o surgimento de relações sinérgicas. A palavra sinergia vem do grego - syn (junto) e ergo (trabalho) - e significa trabalho em conjunto. Relações sinérgicas indicam que o comportamento de um sistema total não pode ser previsto pelo comportamento de suas partes (BERTALANFFY, I977), ou seja, deve-se trabalhar em conjunto, cooperativamente. De acordo com Fuller (I982), sinergia entre empresas é uma forma coletiva de proceder, de modo que os resultados alcançados sejam mais significativos do que a soma de tudo que se conseguiria em separado.

Em um sentido sinérgico, arranjos produtivos locais (APLs) são entendidos como aglomerações com território definido e agentes envolvidos em sua constante transformação, que possuam atividades de interesse em comum e também uma conexão entre si. Assim, os arranjos produtivos locais, por terem um caráter inovativo e evolutivo, possuem relações de interdependência entre os atores, são bem articulados com seus pares/parceiros e clientes em potencial, além de terem um vínculo consistente. Em relação à estratégia adotada por essas aglomerações, os APLs proporcionam benefícios reais para as empresas, em especial à micro e pequena empresa, pois alavancam o empreendedorismo, buscam inovação constante, propiciam a redução de custos em relação à economia de escala e a flexibilidade de ação de cada um (LASTRES; CASSIOLATO, 2005).

Apesar de serem relevantes, os benefícios apresentados não esgotam as possibilidades advindas do surgimento de APLs. No início da década de I990, Elkington (2OI2) propôs um modelo para avaliação de comportamentos sustentáveis nas organizações, o triple bottom line. O modelo integra os três Ps - people, profit e planet -, incluindo, além do desempenho financeiro, o social e o ambiental na criação de valor para o negócio. Sendo assim, com a evolução do próprio conceito de desenvolvimento, mediante o fortalecimento do paradigma da sustentabilidade, torna-se necessária uma evolução das discussões em torno dos APLs que incorpore ponderações acerca de tais dimensões.

Dessa forma, este estudo tem como objetivo geral analisar a ocorrência de práticas de desenvolvimento sustentável, com base no modelo triple bottom line, em um arranjo produtivo local. Para tanto, escolheu-se como campo empírico 
de estudo um APL de móveis, localizado no município de Marco, no Estado do Ceará. Sua escolha para este trabalho deveu-se primeiramente às características desse tipo de atividade que, por depender da extração e utilização de recursos naturais, principalmente a madeira, apresenta grande relação com questões da dimensão ambiental da sustentabilidade. Além disso, essa escolha também se deve aos aspectos relativos à própria região onde o APL se concentra, uma região pouco desenvolvida e carente de ações que visem ao desenvolvimento de sua população. Finalmente, o reconhecimento do forte desempenho econômico do APL de Marco, que fez com que a cidade fosse reconhecida como um dos maiores polos moveleiros do Norte e Nordeste do país, reforça a necessidade de investigar as suas ações nas três dimensões citadas.

Em relação à metodologia da pesquisa, optou-se pela utilização de uma abordagem qualitativa, aplicada mediante utilização de estudo de caso. Os sujeitos escolhidos como fonte de dados acerca do APL de Marco, empreendedores do próprio APL, foram selecionados intencionalmente e por acessibilidade. Além das entrevistas conduzidas mediante roteiro semiestruturado, foram colhidos dados por meio de observação sistemática e análise de documentos, avaliados por meio da técnica de análise temática.

Este estudo é oportuno no sentido de que o arranjo produtivo analisado poderá ser impactado pelo modelo local de gestão, que se caracteriza pela satelitização (FILION; LUC; FORTIN, 2003). A empresa satélite pode alterar as forças competitivas que equilibram a competição entre empresas, facilitando a entrada de novos competidores, desequilibrando a rivalidade entre os concorrentes, o poder de negociação com clientes e fornecedores e a ameaça de substituição por novos produtos (PORTER, I999), o que traria consequências negativas para a competitividade local.

Além disso, o estudo agrega maiores informações e conhecimentos sobre a concentração de negócios que formam "territórios alternativos", cujo propósito é a construção de um espaço mais igualitário econômica, ambiental e socialmente (HAESBAERT, 2002). Assim, espera-se que este estudo possa contribuir para o entendimento acerca das relações entre as diversas dimensões do desenvolvimento sustentável e as práticas observadas no contexto dos APLs. Ademais, acredita-se que uma avaliação das práticas existentes no APL de móveis de Marco tende a auxiliar na construção de políticas públicas que fortaleçam o desenvolvimento das atividades econômicas do município, melhorando a qualidade de vida de sua população e preservando os recursos naturais presentes na região. 


\section{ARRANJOS PRODUTIVOS LOCAIS: ABORDAGENS TEÓRICAS}

Um pequeno grupo de economistas italianos - Bagnasco (1977), Brusco e Sabel (I98I), Fuà (1983) e Becattini (I987) - teorizou, em meados da década de I970, sobre a sinalização de um novo modelo de crescimento mesmo nos setores tradicionais da indústria manufatureira da época, que não se enquadrava nas mudanças que ocorriam em relação ao desenvolvimento econômico vigente. Essas mudanças tinham como característica uma distribuição de territórios de pequenas e médias empresas que se organizavam de maneira peculiar, com a participação da comunidade local. Tal acontecimento tinha uma identidade e dinamismo surpreendentes que preconizavam poucos elementos, como: um tipo de especialização de um setor manufatureiro, a cooperação e competição ao mesmo tempo entre essas pequenas e médias empresas, empreendedorismo entre a comunidade e um tipo de continuidade entre vida social e econômica.

$\mathrm{Na}$ intenção de captar a diversidade dessas experiências, Schmitz (I999) propôs um tipo de organização dos conceitos utilizados com suas mais diversas abordagens para vinculá-las a características peculiares com o intuito de manter uma maior convergência. Assim, expressões e termos como distritos industriais, clusters, milieu innovateur, sistemas produtivos, sistemas regionais de inovação, sistemas locais de inovação, entre outros, mesmo originados de abordagens teóricas das mais diversas, apresentam certa concentração de ideias no tocante à dimensão localizada da inovação e da competitividade.

Segundo o autor, são quatro as linhas principais das variadas correntes de pensamentos:

- A economia neoclássica tradicional, também conhecida como a nova geografia econômica, vislumbrava, na década de I980, a chamada nova teoria do crescimento e comércio internacional, surgida por meio dos retornos crescentes originados das aglomerações (KRUGMAN, I995).

- De acordo com Porter (I999), na economia e gestão das empresas, percebem-se fatores e atores locais com seus vínculos atrelados ao dinamismo de empresas líderes, as quais buscam vantagem competitiva, com ênfase na rivalidade local a partir das redes de fornecedores. Destaca-se aqui a abordagem de clusters liderada por Scott (I988).

- Abordada frequentemente na literatura sobre distritos industriais, a terceira corrente refere-se à economia e ciência regional. Ela surgiu primeiramente na Itália e depois se expandiu para outros países da Europa e outros continentes (PIORE; SABEL, I984; BRUSCO, I990; BECATTINI, I990; PIKE; 
SENGENBERGER, I992; MARKUSEN, I996). Vale ressaltar as diversas contribuições sobre o efeito do aprendizado e da inovação, com destaque aos sistemas de inovação em níveis regional e local (STORPER, I995), e a abordagem de milieu innovateur, em que a potencialidade institucional endógena no nível local é empregada para elucidar a enérgica dinâmica inovativa das empresas (CAMAGNI, I99I).

- Por fim, existe a economia da inovação, em que a integração dos atores locais para o aprendizado e o caráter focado para inovação reforçam o conceito de sistemas nacionais de inovação (FREEMAN, I987; LUNDVAL, I992) e aquele referente a sistemas regionais e locais de inovação (COOKE, I996; EDQUIST, I997; CASSIOLATO; LASTRES, I999).

Observa-se que tais conceitos tendem a combinar diversas contribuições de várias correntes de pensamento. Assim, como a mais importante concentração entre tais conceitos, reconhece-se totalmente que as fontes locais de inovação e competitividade são cruciais para o desenvolvimento. O retorno dos entendimentos de Marshall (I985) se deu pelo argumento das externalidades dinâmicas (em que o processo de inovação das firmas é originado por meio de relações interfirmas e atores que atuam em processos inovativos) e das economias externas (em que a expansão dos mercados é obtida pelo desenvolvimento de métodos e ferramentas comerciais, e pela origem de chances de novos agentes ofertarem seus serviços e pela especialização), que são importantes no campo de economistas como Becattini (I990), Pike e Sengenberger (1992), Storper (I995) e Schmitz (I999), por exemplo.

Segundo Coró (I999), a noção de território é de suma importância para a articulação efetiva de aglomerado produtivo de empresas, pois uma aglomeração ocorre em um espaço definido, onde há vários atores envolvidos, como empreendedores, empresários, entidades de apoio etc., que se instalam, produzem e se integram nesses territórios. Assim, é o "local" que promove a união dos atores do arranjo produtivo, "o lugar, a região não são mais o fruto de uma solidariedade orgânica, mas de uma solidariedade regulada ou organizacional” (SANTOS, I993, p. 20).

O termo sinergia se insere no local e é entendido por Boisier (2003, p. 28) como "a capacidade coletiva para realizar ações em comum sobre a base de uma mesma interpretação da realidade e suas possibilidades de mudança”. Percebe-se assim o crescimento de aglomerados que valorizam as características locais ao invés da hegemonia global. Dessa maneira, há a valorização maciça da cultura da região local, ao contrário da simples aceitação passiva de elementos de culturas diversas que nada têm em comum com as tradições e peculiaridades locais. 
Assim, Santos (2000) relata outra forma de enxergar a noção de território: um espaço onde se constroem valores, identidades e laços de cooperação que se opõem à chamada "alienação territorial" consagrada pelas corporações globalizadas.

\subsection{EMPRESÁRIO POLÍTICO OU EMPRESÁRIO COLETIVO}

Cocco, Galvão e Silva (I999) utilizam o modelo italiano para assim propagarem elementos os mais abrangentes possíveis com o intuito de propor políticas públicas de desenvolvimento condizentes com a realidade brasileira. Assim, surge a figura do "empresário político" ou "empresário coletivo" e suas relações com os chamados atores produtivos: "analisaremos como o regime produtivo centrado nos territórios traz modificações para o próprio processo cooperativo, abrindo espaço para a afirmação de um empresariamento de tipo político" (COCCO; GALVÃO; SILVA, I999, p. 2I).

Assim, quando os empresários trabalham de uma maneira cooperativa buscando uma maior atuação no campo social em vez das relações, única e exclusivamente econômicas e financeiras, eles precisam desempenhar um papel mais político com seus parceiros.

Segundo Negri (I999), a aptidão do empresário político está voltada à mobilização de recursos e soluções e à realização de sinergias produtivas por meio das relações culturais e econômicas que formam o "local". Além disso, o empresário político age nos processos de cooperação, "porque o político é a forma de existência e de expressão do social” (NEGRI, I999, p. 66).

Para um maior embasamento teórico, os tópicos abordados adiante tratam de uma revisão da literatura sobre desenvolvimento sustentável, com o propósito de investigar a realidade que ocorre no arranjo produtivo local moveleiro do município de Marco - CE.

\section{DESENVOLVIMENTO SUSTENTÁVEL}

Sachs (2008) ressalta que os estudos pioneiros acerca do termo desenvolvimento propagavam, na sua origem, a importância do pleno emprego atrelada ao valor do Estado de Bem-Estar e a obrigação da intervenção do Estado em assuntos econômicos com o intuito de atenuar a indiferença dos mercados.

Wolfe (I973), Pinto (I976), Sunkel (I980) e Gudynas (1989) abordaram alguns pontos sobre estilos alternativos de desenvolvimento no tocante à conservação do meio ambiente: I. é necessário renunciar à fé cega de crescimento econômico exponencial ilimitado; 2. se houver exportação dos recursos naturais 
nativos, não existirá um desenvolvimento sustentado; 3. deve-se conter o ritmo frenético da degradação ambiental; e 4. o objetivo principal de qualquer desenvolvimento é baseado na qualidade de vida. Assim, tais estilos alternativos de desenvolvimento que ressaltavam o valor da conservação ambiental receberam outras denominações, como ecodesenvolvimento, desenvolvimento sustentável, desenvolvimento alternativo.

A partir desse contexto, surgiu a proposição de um novo estilo de desenvolvimento, denominado de ecodesenvolvimento, que, segundo Sachs (I973), foi introduzido pelo canadense Maurice Strong no início da década de I970, para apaziguar a dicotomia "economia-ecologia" e diferenciar uma visão alternativa de política de desenvolvimento. O ecodesenvolvimento foi designado como um tipo de estratégia de desenvolvimento que não permitia que houvesse degradação ambiental por conta do crescimento econômico. Assim, surgia uma proposta de uma nova ética de desenvolvimento, em que só se utilizavam os recursos naturais realmente necessários de cada ecossistema pelos habitantes locais. Tal estratégia de desenvolvimento tinha como premissa a melhora da qualidade de vida da população de um modo geral e a satisfação de suas necessidades básicas.

A concepção de ecodesenvolvimento retratou, primeiramente, as regiões rurais da África, Ásia e América Latina, o que gerou uma perspectiva das inter-relações entre subdesenvolvimento e superdesenvolvimento em nível global. Observa-se que os debates acerca do ecodesenvolvimento foram necessários e oportunos, pois resultaram na adoção futura da expressão desenvolvimento sustentável (GLAESER; UYASULU, I984).

Segundo Veiga (2006, p. I89), a proposta do ecodesenvolvimento "sobreviveu" por pouco tempo, pois

Na verdade, a expressão desenvolvimento sustentável foi a que acabou se legitimando para negar a incompatibilidade entre o crescimento econômico contínuo e a conservação do meio ambiente. Ou ainda, para afirmar a possibilidade de uma conciliação desses dois objetivos, isto é, de crescer sem destruir. Essa legitimidade foi conquistada em oposição à idéia de "ecodesenvolvimento", preferida por algum tempo pelos principais articuladores do processo internacional que levou à Conferência do Rio, em I992.

Já a expressão desenvolvimento sustentado (criada na mesma época) obteve destaque, pois foi utilizada em apontamentos importantes como Estratégia mundial para a conservação (IUNC, I980), Nosso futuro comum (WORLD COMMISSION ON ENVIRONMENT AND DEVELOPMENT, I987) e Informe da Comissão de Desenvolvimento e Meio Ambiente da América Latina e Caribe, de I99I. 
Segundo a World Commission on Environment and Development (I987), a definição de sustentabilidade está fundamentada no equilíbrio entre os recursos ambientais e as necessidades da sociedade, de maneira a não comprometer as futuras gerações.

A expressão desenvolvimento sustentável é considerada promissora, porém difícil e complexa, pois engloba mudanças estruturais, além de contar com resistências das mais diversas no âmbito social e político, herdadas de hábitos enraizados dos países e segmentos sociais mais abastados. Apesar dessas controvérsias, o desenvolvimento sustentável possui premissas necessárias que permitem uma referência concreta para o desenvolvimento (BUARQUE, 2006). Observa-se que, nos dias atuais, as pessoas têm mais consciência no tocante à insustentabilidade "que decorre da recusa a aceitar a pobreza e as desigualdades sociais e dos elevados custos sociais do crescimento econômico, levando à ampliação de sistema de regulação" (BUARQUE, 2006, p. 62).

Segundo Sachs (2002), a sustentabilidade é vista como um processo dinâmico em que o esforço e o compromisso dos atores devem ser constantes e cíclicos. Depois de cumprida, cada meta deve ser reavaliada para assim obter uma melhoria contínua, o que implica a evolução constante e gradual do desenvolvimento sustentável (CALLENS; TYTECA, I999).

\subsection{TRIPLE BOTTOM LINE}

A expressão triple bottom line (TBL) foi formulada por John Elkington, considerado uma autoridade mundial em responsabilidade corporativa e desenvolvimento sustentável. Tal expressão foi criada em I995 para difundir a ideia de concepção de valor multidimensional baseada em três componentes do desenvolvimento sustentável: people, planet \& profit (pessoas, planeta \& lucros) (ELKINGTON, 2OI2).

O TBL surgiu para auxiliar as empresas de petróleo e gás a integrar os três pilares do desenvolvimento sustentável - prosperidade econômica, justiça social e proteção ao meio ambiente - nas suas transações mais importantes e a transpor a sustentabilidade da teoria para a prática. Assim, o planejamento estratégico das empresas passa a incorporar um novo comportamento, intitulado triple bottom line por conta do intrínseco relacionamento das dimensões econômicas, sociais e também ambientais (ELKINGTON, 20I2).

Apesar de ter sido desenvolvido para auxiliar empresas a integrar os três pilares do desenvolvimento sustentável, o modelo do triple bottom line pode ser adequado do ambiente corporativo para outros formatos organizacionais, como arranjos produtivos locais, conforme pode ser observado na Figura I. 


\section{FigurA I}

\section{MODELO TRIPLE BOTTOM LINE E}

OUTROS FORMATOS ORGANIZACIONAIS

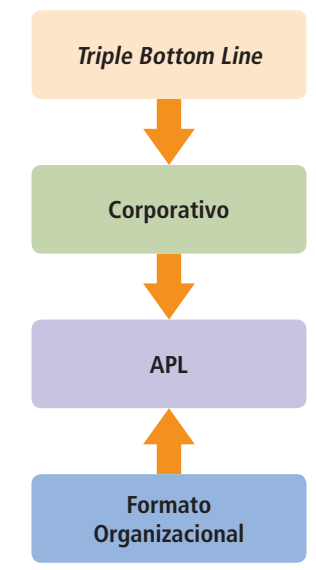

Fonte: Elaborada pelos autores.

De acordo com os novos modelos de negócios, as empresas hoje possuem obrigações perante toda a sociedade. O conceito de sustentabilidade corrobora a concepção de que as organizações devem se preocupar em minimizar os impactos ao meio ambiente, e as sociedades simultaneamente, e em consequência, propagam a criação de valor aos seus acionistas (HART, I997; CARROL, I999; STEGER, 2004).

Para Winn e Kirchgeorg (2005), a sociedade, as organizações e o Estado compreendem que qualquer avanço na sustentabilidade empresarial acarreta uma compensação que vai além do aspecto econômico-financeiro, almejando o equilíbrio, a equidade social e a resiliência ambiental para a busca de soluções de longo prazo e também de ganha-ganha (win-win). As empresas precisam de estratégias que lhe rendam benefícios e, simultaneamente, a seus clientes e ao meio ambiente (win-win-win strategies) (ELKINGTON, 20I2).

Segundo Almeida (2002), a expressão triple bottom line (TBL) e a palavra sustentabilidade são termos ainda em construção não somente no Brasil, mas também no mundo inteiro. A expressão tiple bottom line é utilizada em inglês porque ainda não há uma tradução apropriada, embora possa entendida como "tripolaridade". O autor explica que o TBL reflete um conjunto de valores, metas, objetivos e procedimentos com o foco de criação de valor econômico, social e ambiental que juntos trabalhem em harmonia para evitar qualquer tipo de dano a partir de sua atuação. 


\section{PROCEDIMENTOS METODOLÓGICOS}

Tendo como objetivo analisar a ocorrência de práticas de desenvolvimento sustentável, com base no modelo TBL, em um arranjo produtivo local, esta pesquisa utilizou-se de uma abordagem qualitativa, pois se reconhece que estudos que envolvem o tema desenvolvimento são permeados pela interdisciplinaridade, e qualquer tentativa de reducionismo pode minimizar a riqueza das informações e limitar o significado das interpretações. Dentre as possibilidades de metodologias qualitativas existentes, a estratégia de estudo de caso foi escolhida por possibilitar, segundo Yin (2005), uma investigação que preserve as características holísticas e importantes dos acontecimentos da vida real, como os ciclos de vida individuais, os processos organizacionais e administrativos, as modificações ocorridas em regiões urbanas, as relações internacionais e a maturação de setores econômicos.

Casos podem ser constituídos por indivíduos, grupos, programas, organizações, culturas, regiões, Estados, incidentes críticos, fases na vida de uma pessoa, ou seja, qualquer evento que possa ser definido como um sistema delimitado, específico, único (PATTON, 2002). Neste estudo, o caso foi constituído pelo conjunto de empresas inseridas no arranjo produtivo local da indústria moveleira do município de Marco, no Estado do Ceará. Como o estudo de caso apresenta um caráter particularizante e tem um poder de generalização limitado (BRUYNE; HERMAN; SCHOUTHEETE, I977), os resultados obtidos em Marco não deverão ser generalizados para outros contextos semelhantes, principalmente porque está ocorrendo nesse município um fenômeno atípico, em relação a cidades geográfica e demograficamente semelhantes. Assim, o que está se pretendendo não é generalizar, mas analisar manifestações do desenvolvimento sustentável em um arranjo produtivo situado no semiárido cearense. Por fim, em territórios diferentes, arranjos produtivos locais apresentam nuanças próprias, que contribuem para a variabilidade nas formas de organização dessas configurações (MCNAUGHTON, 2000), não sendo desejável a generalização de dados obtidos em um arranjo específico.

Com relação aos sujeitos da pesquisa, optou-se pelo grupo de empreendedores inseridos no APL de Marco. Esses sujeitos foram escolhidos intencionalmente e por acessibilidade, sendo entrevistados seis empreendedores que estão vinculados à indústria moveleira, inclusive o representante do sindicato patronal, o presidente do Sindicato das Indústrias do Mobiliário (Sindmóveis) do Ceará e proprietário da terceira maior empresa de móveis da cidade. As entrevistas foram realizadas no município de Marco, no período de I 6 de abril a I 8 de maio de 2012 , e tiveram duração aproximada de 30 a 40 minutos. Com o consentimento dos respondentes, todas as entrevistas foram gravadas, para posterior transcrição. 
O protocolo de entrevista consistiu em uma solicitação para o entrevistado "contar" sobre o APL de Marco, sobre o que está acontecendo em relação à influência da indústria de móveis no cenário do município e sobre a existência de políticas públicas referentes a educação, saúde, meio ambiente, pois as pessoas se sentem mais confortáveis narrando um processo, a partir da expressão "conte o que acontece" (SPINK, 2003). Em complemento, a observação direta também foi utilizada como fonte de coleta, porque possibilita ver o que não é percebido rotineiramente, além de fatos que as pessoas não informariam voluntariamente, possibilitando ir além da percepção dos outros, desenvolvendo uma visão mais compreensiva (PATTON, 2002).

Ademais, foi realizada uma pesquisa documental consistente que fundamentou os dados obtidos pelas entrevistas e pela observação. O corpus documental foi construído com base em "dados macrossociais, que apenas organismos oficiais poderosos, como os institutos nacionais de estatística, têm condições de recolher" (QUIVY; CAMPENHOUDT, 2008, p. 20I). Assim, foram obtidos dados do Instituto Brasileiro de Geografia e Estatística (IBGE), Ministério do Trabalho e Emprego/Relação Anual de Informações Sociais (Rais), Instituto de Pesquisa e Estratégia Econômica do Ceará (Ipece) e dados do Anuário Estatístico do Ceará.

Vale ressaltar que, em pesquisas qualitativas, a análise dos dados geralmente tem início junto com a coleta, com o intuito de validar as informações obtidas (MERRIAM, I998; PATTON, 2002). Posteriormente, os dados obtidos em campo foram examinados por meio da análise temática, uma técnica de verificação de conteúdo que "consiste em descobrir os núcleos de sentido que compõem uma comunicação, cuja presença ou frequência signifiquem alguma coisa para o objeto analítico visado" (MINAYO, 2007, p. 316).

\section{LÓCUS DA PESQUISA: O APL MOVELEIRO DE MARCO (CE)}

O município de Marco foi fundado em 22 de novembro de I95I, possui uma extensão territorial de $574 \mathrm{~km}^{2}$ e tem 24.703 habitantes, segundo dados do Instituto Brasileiro de Geografia e Estatística (2010). Distante $234 \mathrm{~km}$ de Fortaleza, Marco tem como uma de suas principais atividades econômicas a fabricação de móveis e é considerado o maior polo moveleiro do Ceará. A proximidade dos empreendimentos de móveis já existentes no município e o nível de cooperação entre eles resultaram em um polo moveleiro (LIMA, 2007). 
FIGURA 2

\section{MAPA DE LOCALIZAÇÃO DO APL DE MARCO}

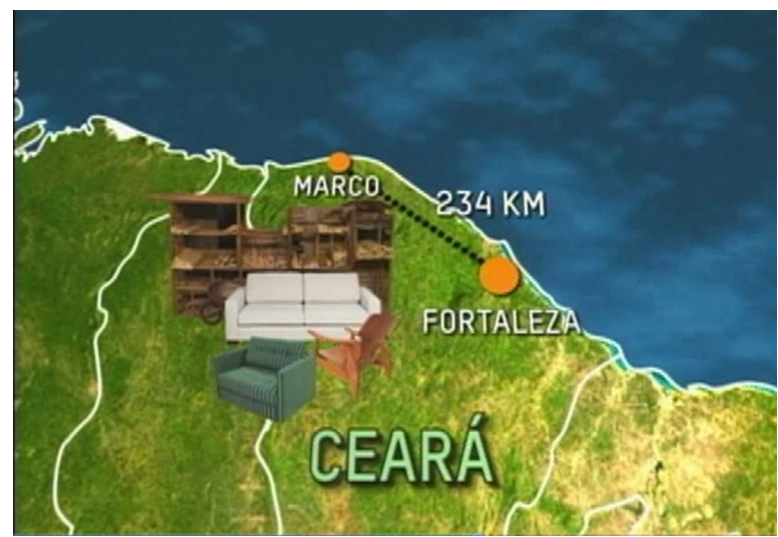

Fonte: Elaborada pelos autores.

O setor moveleiro local se desenvolveu por um sistema de apoio orientado pela demanda que ataca um dos maiores problemas enfrentados pela maioria das pequenas e médias empresas, a comercialização. Esse sistema procura minimizar a constante luta da pequena empresa para encontrar um cliente confiável e, com isso, ter garantia suficiente para o futuro. Tendo para quem produzir, as pequenas empresas passam a ser capazes de concentrar seus esforços na melhoria da produtividade e qualidade do produto (TENDLER, I997; AMORIM, I998).

O impacto das compras governamentais foi muito positivo, e as cidades e suas serrarias não ficaram dependentes da continuidade desses contratos. Elas usaram suas novas habilidades e contatos estabelecidos com os fornecedores para que pudessem se lançar em outros mercados privados (SCIPIÃO, 2000).

A entrada no ramo moveleiro foi lenta e progressiva, pois os integrantes que eram incentivados a montar seu negócio não tinham nenhuma tradição em fabricar móveis. Vinham das mais diversas origens, como tabeliães de cartório, proprietários de fábricas de calçados e até ex-funcionários públicos. Uma primeira pessoa aceitava o desafio de produzir móveis, e, ao obter sucesso, outras se motivavam também a entrar no ramo. Com a total garantia de venda de seus produtos, contatos com fornecedores, capacitação da mão de obra, os novos empresários eliminavam muitas das barreiras para montar um negócio (LIMA, 2007).

Em I996, Marco possuía I8.352 habitantes, segundo o Instituto Brasileiro de Geografia e Estatística (I996), e 39 indústrias de transformação. Em I992 houve a abertura da primeira fábrica de móveis no município, gerando uma nova realidade comercial com a origem do polo industrial, em I996. O polo do 
município de Marco tornou-se referência no setor moveleiro, gerando emprego e renda para todos os habitantes tanto do próprio município como de outros vizinhos. Vale ressaltar que essa evolução estava alicerçada em dois importantes pilares: uma cultura voltada para cooperação de todos e, o principal, a vocação moveleira (BRASIL, 2008).

A partir desse progresso, Marco hoje é um município rodeado dos mais variados portes de fábricas de móveis e agregados (componentes de alumínio, granitos e mármores, vidros etc.), desde as pequenas e médias empresas até as de grande porte e também as minifábricas localizadas nas garagens de algumas residências. Assim, evidenciam-se a geração de emprego e renda e a evolução da cidade. Dessa forma, a constatação de Sengenberger e Pike (I999, p. I02) no tocante a uma nova organização social e econômica de pequenas empresas, com uma especificidade local, ou seja, uma delimitação geográfica onde existe uma coesão social, e também no que se refere à disponibilidade dessas novas organizações em cooperar entre si com ideias e inovações, destaca-se na evolução no APL de Marco.

\section{DEMONSTRAÇÕES ECONÔMICAS (PROFIT), SOCIAIS (PEOPLE) E AMBIENTAIS (PLANET)}

No Índice de Desenvolvimento Humano (IDH), que pode ser entendido como uma avaliação resumida do progresso em longo prazo em três dimensões básicas do desenvolvimento humano como a renda, a educação e a saúde, o município de Marco está na $94^{\circ}$ posição no ranking, entre os I84 municípios do Estado do Ceará avaliados no estudo, divulgado pelo Programa das Nações Unidas para o Desenvolvimento (20I2) com base no ano de 20IO: "É importante lembrar que Marco é uma cidade pequena e pobre ainda, como várias do interior do Ceará e do Nordeste" (entrevistado 6).

Os empreendedores locais enxergam isso como uma fase necessária ao desenvolvimento, pois argumentam que a cidade é pequena e pobre como a grande maioria do Ceará e do Nordeste. Mas eles não pensam na estagnação, e sim na força do trabalho e no crescimento. Como relata Sachs (I986), o desenvolvimento abrange as dimensões econômicas, sociais, culturais, ecológicas e espaciais, as quais são evidenciadas quando ocorre um processo de crescimento que seja determinado ou condicionado; essas dimensões podem estar reunidas ou sozinhas. Vale ressaltar o caso da Terceira Itália abordado por Bagnasco (200I): os fatores sociais, produtivos e políticos, após serem integrados, foram 
impulsionados e reconhecidos como um meio de desenvolvimento de regiões pobres. De acordo com Gallicchio (2003), há um "outro desenvolvimento" sustentável, integral e inclusivo, cujo objetivo é melhorar a qualidade de vida de todos com o manejo das potencialidades locais.

Em relação ao Produto Interno Bruto (PIB), o município de Marco apresentou uma evolução no período de 2002 a 2008 (ver tabelas i e 2), o que demonstra um impacto direto na população, pois, segundo alguns economistas, os números são indicadores determinantes da qualidade de vida e revelam um crescimento econômico. O APL de Marco colaborou para a alavancagem do comércio na cidade e com isso conduziu uma movimentação de bens e serviços.

\section{TABELA I}

EVOLUÇÃO DO PRODUTO INTERNO BRUTO

\begin{tabular}{lrrrrrrr}
\hline & \multicolumn{7}{c}{ ANO } \\
\cline { 2 - 8 } DISCRIMINAÇÃO & 2002 & 2003 & 2004 & 2005 & 2006 & 2007 & 2008 \\
\hline $\begin{array}{l}\text { PIB a preços de mercado } \\
\text { (R\$ mil) }\end{array}$ & 35.437 & 35.437 & 64.165 & 66.733 & 73.100 & 82.170 & 96.188 \\
\hline PIB per capita (R\$ 1,00) & 1.740 & 2.240 & 3.163 & 3.295 & 3.615 & 3.556 & 3.967 \\
\hline
\end{tabular}

Fonte: Instituto de Pesquisa e Estratégia Econômica do Ceará (20I2).

\section{TABELA 2}

PRODUTO INTERNO BRUTO POR SETOR (\%)

\begin{tabular}{|c|c|c|c|c|c|c|c|}
\hline \multirow{2}{*}{ SETORES } & \multicolumn{7}{|c|}{ ANO } \\
\hline & 2002 & 2003 & 2004 & 2005 & 2006 & 2007 & 2008 \\
\hline Agropecuária & 12,2 & 13,29 & 9,91 & 10,12 & 15,09 & 15,6 & 15,59 \\
\hline Indústria & 10,1 & 28,2 & 21,35 & 16,37 & 16,74 & 17,8 & 17,83 \\
\hline Serviços & 77,7 & 58,51 & 68,73 & 73,51 & 68,17 & 66,6 & 66,58 \\
\hline
\end{tabular}

Fonte: Instituto de Pesquisa e Estratégia Econômica do Ceará (20I2).

Além disso, com o aumento no número de pessoas empregadas, gerou-se uma melhora no padrão de renda per capita do município, como ressalta um dos entrevistados: "Com certeza a renda aqui no Marco melhorou muito" (entrevistado 4). Nesse sentido, os dados da pesquisa revelam que cada família, em 
cada domicílio, tem, pelo menos, duas pessoas trabalhando, como o marido e a esposa. E os filhos também participam da renda familiar como uma forma de aprender o ofício dos pais: "Antigamente era só o dono da casa que trabalhava. Hoje é o dono, a mulher, o filho. Se tiver dois filhos, trabalham também” (entrevistado 3). Ademais, de acordo com a visão de um empresário local, o aumento do parque fabril, por exemplo, é um bom indicador do crescimento do PIB da região (entrevistado 6).

Outro aspecto observado na pesquisa se deu em relação à questão da geração de emprego e renda dentro da formalidade, ou seja, com empregos com carteira de trabalho assinada e, em consequência, o aquecimento do comércio local.

Porque se você colocar I.700 funcionários, cada um ganhando, no mínimo um salário (que tem pessoas que ganham mais), então você já injetou na economia local mais de R \$ I.000.000,00, não é? Então, você tem, no mínimo, R \$ I.000.000,00 todo mês circulando na cidade de 25.000 habitantes. Então, essas pessoas estão comprando eletrodoméstico, estão comprando moto, estão comprando carro, estão construindo casa e o comércio local muito aquecido, devido às empresas. Então, a renda está muito boa (entrevistado I).

Como ressaltam Kliksberg (I997), Sen (2000) e Sachs (2002), o desenvolvimento vai além da simples expressão "desenvolvimento e crescimento econômico" preconizada pelos países desenvolvidos, pois não ameniza nem resolve a desigualdade social, a pobreza e exclusão social. Dessa forma, uma nova visão sobre fatores como a qualidade e a estrutura do crescimento, analisadas sob o impacto que elas podem causar no emprego, no meio ambiente, na qualidade de vida, na distribuição de renda e no exercício da cidadania, é crucial para o bem-estar da população.

Os dados da pesquisa apontam que a condicionante moradia dos habitantes da cidade de Marco melhorou bastante nos últimos anos. Em toda a cidade, veem-se novas construções tanto residenciais como comerciais, além de terrenos para agricultura. Segundo os entrevistados:

Hoje se você andar nessas ruas aqui do Marco, você vai ver que em cada quarteirão tem uma construção (entrevistado 2).

Tanto faz ter a casa do pobre ou do rico [...]. Suas casas são todas ajeitadas, de piso bom, móvel bom (entrevistado 3). 
- RAFAELLA ALVES M. ALVARENGA • FÁTIMA REGINA NEY MATOS • DIEGO DE QUEIROZ MACHADO • - MICHELLE DO CARMO SOBREIRA • LORENA BEZERRA DE SOUZA MATOS •

Já tem gente comprando terreno, grandes terrenos, preparando para começar a plantar (entrevistado 6).

Hoje Marco é reconhecida como a "cidade do trabalho", e seus habitantes a consideram como seu trabalho, e o entretenimento fica para os municípios vizinhos. Apesar das festas promovidas pelo APL de Marco e pelos Fabricantes Associados de Marco (Fama), como Dia do Trabalho, Confraternização de Natal e o tradicional Chitão Maravilha de Marco (que é uma festa realizada todo mês de julho), os empreendedores alegam que não há nenhum tipo de entretenimento. Para o entrevistado 3: "Marco é uma cidade que respira trabalho, é impressionante". O entrevistado 4 complementa: "O povo ganha dinheiro aqui e gasta nas outras cidades".

Fica na calçada! Pouquíssimo! Aqui não tem. Aqui é missa, casa e trabalho. Meu passeio é na igreja. Não tem divertimento. Uma festa no ano que é boa é o Chitão que vai realizar agora em julho. Tem missa e depois todo mundo vai para sua casa (entrevistado 2).

A cultura local é valorizada, o que corrobora a visão de Santos (2000) sobre o território como um espaço onde se constroem valores, identidades e laços de cooperação.

A saúde é um item muito delicado, pois os empreendedores entrevistados foram unânimes em dizer que a saúde da cidade é muito precária. A grande maioria se trata em Sobral ou mesmo em Fortaleza. De acordo com os empreendedores, a saúde do município melhorou depois da formação do APL de Marco, sobretudo por causa do aumento de poder aquisitivo da população, e não por iniciativa dos órgãos públicos: "Acredito que mais pelo poder aquisitivo do que por ações públicas. Hoje a pessoa tem condições de comprar remédio, pode ir para Sobral ou Fortaleza" (entrevistado I). Já o entrevistado 6 complementa: "Quando você aumenta o poder aquisitivo, diminui a dependência da área de saúde. Você aí tem condições de remédio, de exame, de tudo".

Sachs (2008) defende que a sociedade precisa do mínimo necessário para seu bem-estar e qualidade de vida para assim poder prosperar e viver bem. Assim, serviços públicos, como saúde, educação, moradias decentes, água potável e saneamento básico, têm que fazer parte de estratégia de desenvolvimento. Somente dessa maneira poderá existir um sentido de equidade, de igualdade e solidariedade entre as pessoas de um local, região ou país, com a superação da pobreza em um mundo com tanta abundância. 
O quesito educação é entendido pelos empreendedores em relação à falta de mão de obra mais qualificada para atuar nas empresas. Existe a carência de pessoas com especialização necessária para gerir, liderar e administrar um negócio. Mão de obra para o trabalho mais rotineiro, como operador de máquina e costureira, existe em abundância, até porque esses ofícios foram ensinados desde o início das fábricas: "Passou de família para família" (entrevistados I, 3, 4 e 5). Já o entrevistado 6 desabafa: "A gente sente falta de uma pessoa de uma qualificação melhor, como um encarregado, por exemplo. Uma pessoa que seja líder, motivador".

Para lidarem com essa problemática, os empresários do APL de Marco e a prefeitura (na qual, à época, trabalhavam familiares da grande maioria dos empreendedores do município) passaram a desenvolver projetos em parceria com o Instituto Euvaldo Lodi (IEL), o Serviço Brasileiro de Apoio às Micro e Pequenas Empresas (Sebrae) - com aplicação de programas de capacitação - e Fama. Essa ação dirigida para a educação gerou um impulso de crescimento nessa nova geração, pois o APL de Marco já possui a vocação de trabalhar com móveis, mas é preciso qualificar essa mão de obra para assumir cargos mais altos, como de liderança. $\mathrm{O}$ entrevistado 6 comenta entusiasmado:

Estamos tentando um centro tecnológico aqui para o Marco. Esse centro tecnológico vai abordar espaço para feiras aqui no Marco, laboratórios, auditórios, salas de treinamento, muita coisa legal, mas que ainda está em evolução. Existe já o projeto.

Para Sen (2000), as chamadas oportunidades sociais são entendidas como as condições que a sociedade constitui nas áreas de educação, saúde e saneamento, as quais possuem forte influência para a liberdade de uma pessoa em viver melhor. Tais benesses importam tanto no dia a dia da vida privada de cada indivíduo quanto na integração efetiva das atividades de cunho político e econômico. O autor declara que o chamado desenvolvimento humano "é um processo de expansão da educação, dos serviços de saúde e de outras condições da vida humana" (SEN, 2000, p. 58).

Em relação à infraestrutura da cidade, os empreendedores relatam, principalmente, a falta do funcionamento do saneamento básico. Por meio da iniciativa de um deputado da região, foram iniciadas as obras de saneamento básico em boa parte da cidade, mas ainda não foram concluídas. Boa parte das tubulações já foi instalada, mas as ligações não foram ainda realizadas, pois é preciso de estação de tratamento de esgoto. Os empreendedores enfatizam a iniciativa do deputado da região, pois, segundo o entrevistado 6 , “a estação de tratamento está 
vindo. Então, Marco, há cinco anos, não tinha nada. Hoje, pelo menos uma boa parte está estruturada para receber o saneamento básico". O entrevistados 3 e 5 sabem que o saneamento foi feito, mas não está ainda em uso. Assim, fica só "debaixo da terra", e problemas como as águas na rua e o lixo só serão resolvidos quando o saneamento for efetivado. Em relação ao saneamento, o entrevistado I afirma: "Isso é coisa de prefeito, de governo".

Segundo o entrevistado 4, existe uma preocupação grande voltada à atuação da Superintendência Estadual do Meio Ambiente do Ceará (Semace) em relação às fábricas que, atualmente, trabalham com estufas para envernizar e pintar móveis:

Tem a câmara da tinta, que é ecológica, para a tinta e o verniz evitar a poluição, a intoxicação e não ir para os rios. Além da atuação da Semace, nos preocupamos sim com o ambiente, pois sem ele não existirá trabalho e nem mesmo a própria cidade. O solvente que utilizamos aqui na fábrica é o menos ofensivo, pois evita o cheiro forte para os trabalhadores.

Assim, os empreendedores enxergam essa preocupação como um zelo maior pela sua cidade e também pelo negócio em si. Tanto os empresários, os donos, como seus colaboradores estão engajados em questões como o meio ambiente, o bem-estar e a qualidade de vida de toda a população. Em todas as fábricas visitadas, independentemente do porte, era visível a adoção dessa nova cultura.

Em relação ao meio ambiente, os empreendedores entrevistados se mostraram muito atentos às questões relacionadas, por exemplo, aos resíduos. A maioria das empresas possui a licença da Semace, o que denota responsabilidade das organizações que fazem parte do APL de Marco. Com a estruturação de órgãos ambientais e legislações específicas que ocorreram devido à Conferência das Nações Unidas sobre o Meio Ambiente Humano - a Conferência de Estocolmo de I972 -, as questões ambientais foram evidenciadas, assim como seus impactos socioeconômicos motivados pela não preservação do meio ambiente e pela própria ameaça de extinção da vida no planeta Terra (GALLOPÍN, I988; ANDERSON; BLACKHURST, I992; BECKER, I993; ALBAGLI, I995; BUARQUE, 2006; NASCIMENTO; LEMOS; MELLO, 2008).

Vale ressaltar que a cidade de Marco possui um solo arenoso, é uma região litorânea e com isso atrai muitos ventos. Porém, os empreendedores do APL de Marco, com uma visão além e conscientes da sustentabilidade do negócio, com sua demanda de $1.000 \mathrm{~m}^{3} /$ mês de madeira vinda do Sul, Sudeste e até da Amazônia, buscaram uma ideia: plantar no município as espécies usadas no polo moveleiro. 
Assim, em 2009, os empreendedores de Marco começaram a desenvolver um projeto de silvicultura em parceria com as seguintes instituições: Sindmóveis do Ceará, Fama, Empresa Brasileira de Pesquisa Agropecuária (Embrapa), Departamento Nacional de Obras contra as Secas (Dnocs), Banco do Nordeste, Governo do Estado do Ceará e Instituto de Desenvolvimento Industrial (Indi) da Federação das Indústrias do Estado do Ceará (Fiec). Barquero (200I) considera que os APLs têm um modo de produção do desenvolvimento diferenciado, pois promovem a modernização e a sustentabilidade das micro e pequenas empresas por meio do desenvolvimento local. O autor relata ainda que tais aglomerações tornam-se mais sustentáveis com a capacidade de atender às suas necessidades imediatas, e com isso surgem novas potencialidades por meio das parcerias com o governo e toda a sociedade envolvida. Barbosa (2008) alerta sobre a urgência de aproveitamento de outras maneiras de desenvolvimento econômico, desde que o os recursos naturais e o meio ambiente não sejam prejudicados.

Além de trazer benefícios econômicos relevantes, tal projeto vislumbra o futuro, já que tais espécies arbóreas levam mais de 20 anos para serem cortadas e usadas comercialmente. O projeto está instalado numa área de 8.300 hectares de terra advindos do Projeto de Irrigação do Baixo Acaraú com o intuito de plantios florestais comerciais. Os entrevistados I, 3, 4 e 5 concordam que a cidade de Marco está atenta à questão ambiental, tanto no que se refere à redução de custos da madeira quanto a uma provável nova cultura que se instalará na cidade, a do agronegócio, que poderá gerar ainda mais emprego e renda para o município.

Essa foi uma ideia do presidente do Sindmóveis, do Sr. Júnior Osterno, que, em uma conversa informal em uma das reuniões, lançou a pergunta: "Por que a gente não planta a nossa própria floresta?”. A princípio todos acharam a ideia inviável, e ele foi um grande incentivador. E hoje já é uma realidade. Já foram plantadas várias espécies e lá tem as tradicionais e não tradicionais. Haverá muitos testes que até o momento estão bem positivos (entrevistado 6).

\section{CONSIDERAÇÕES FINAIS}

A experiência inicial de um APL moveleiro no Ceará é avaliada com sucesso nos dias atuais devido ao efetivo desenvolvimento social e econômico e à integração entre as unidades fabris da região, entre outros aspectos. Como perspectiva futura, tem-se o desenvolvimento sustentável baseado em um constante processo de mudança, em que a exploração e o abuso de recursos, o direcionamento de investimentos etc. buscam atender às necessidades do presente e do futuro em 
equilíbrio. Tal equilíbrio se dá pela preocupação com a geração atual e futura, com o crescimento e sua qualidade, e integrando considerações econômicas e ambientais nas tomadas de decisão, no intuito de preservar a base ecológica para o desenvolvimento.

As relações de trabalho se caracterizam pela cooperação e confiança mútua entre os empreendedores do APL de Marco. Eles percebem que, trabalhando em conjunto e não separadamente, se tornam mais fortes, mais unidos e integrados: "As empresas se completam. A concorrência não é desleal, pois procuramos atender a nichos de mercado diferentes" (entrevistado 6). Os entrevistados I, 2, 3, 4, 5 e 6 relatam que, atuando dessa maneira, o APL se torna mais competitivo no mercado. Cada nova conquista em conjunto gera melhores resultados ao invés de cada um seguir seu caminho em separado, o que corrobora o entendimento de Fuller (I982).

Por meio de uma habilidade em conjunto, podem-se realizar ações com o mesmo entendimento de sua realidade e passível de mudanças (BOISIER, 2003, p. 28). Os empreendedores sabem de sua força em conjunto e valorizam isso. Eles aproveitam o melhor que se tem disponível para um bem comum, o bem do APL e da cidade como um todo. De acordo com Bagnasco (2002, p. 39), "essas condições locais não foram sempre reunidas, mas juntas, criaram esse clima social, cultural e político particular que, numa conjuntura histórica dada, permitiu importantes sinergias entre os parceiros sociais".

Com base no modelo triple bottom line, estão presentes algumas características de desenvolvimento sustentável. Em relação ao meio ambiente, o APL de Marco com suas práticas de produção mais limpa no tocante à diminuição de resíduos por meio do reúso da matéria-prima, por exemplo, mesmo que iniciados por questões de adequação a um órgão regulamentador como a Semace, hoje busca a conscientização ambiental em suas fábricas, além da iniciativa de "plantar sua própria floresta” com o projeto de silvicultura da Embrapa e parceiros. Assim, no quesito planet que se refere a práticas ambientais sustentáveis, o APL de Marco está trilhando seu caminho e buscando melhorias constantes.

Quanto à dimensão econômica, pode-se constatar acentuado progresso por meio da geração de emprego e renda, do aumento populacional e crescimento do PIB. De acordo com a premissa do profit, o lucro é um aspecto reconhecido como um benefício econômico que é apreciado pela população, aliado aos impactos sociais e ambientais.

Sobre a dimensão social, verificam-se os baixos índices de escolaridade, serviços de saúde deficientes, ausência de equipamentos e insumos básicos na escola, a falta de uma faculdade/universidade e de treinamentos para uma qualificação diferenciada. O termo people só pode ter validade quando as ações voltadas ao social são justas e benéficas tanto para as fábricas e seus colaboradores, como 
para toda a população. Assim, confirma-se a deficiência no triple bottom line em relação aos aspectos sociais (people), pois somente as empresas que constituem o APL de Marco não são suficientes para suprir tais demandas em relação à população de um modo geral. $\mathrm{O}$ aspecto social (people) pode ser observado nas fábricas, com seus colaboradores, mas, infelizmente, não traduz a realidade da cidade, pois as demonstrações sociais estão intimamente ligadas à atuação política, mais especificamente do governo municipal.

Apesar dessa situação, pode-se concluir que há perspectiva de mudança desse cenário pela atuação do agente sinérgico no sentido de agir diretamente na política da cidade. Mesmo com a ação de um deputado estadual oriundo de Marco, é vital e necessária a parceria do APL com a prefeitura, pois, dessa forma, as ações poderiam ter uma maior fluidez, os interesses seriam os mesmos. As inovações necessárias são suscetíveis de vir de empresários locais que são capazes de identificar as oportunidades e também enfrentar os desafios ambientais e sociais que possam surgir.

Assim, com uma vasta rede de contatos e a visão criativa dos empresários do APL de Marco atrelado ao agente sinérgico, constata-se que há potencial de avaliação de oportunidades de negócios sustentáveis baseados no valor econômico, social e ambiental que podem surgir a partir de uma simples ideia. Diante da importância que a atividade moveleira realizada no APL tem para o município, reconhece-se como fundamental que os entraves ao seu crescimento sejam superados com a convergência de esforços das esferas pública e privada, de forma a fortalecer o desenvolvimento sustentável de toda a região.

\section{CLUSTER AND SUSTAINABLE DEVELOPMENT: A SYNERGISTIC RELATIONSHIP IN THE CITY OF MARCO (CE)}

\section{ABSTRACT}

With the evolution of the concept of development, by strengthening the sustainability paradigm, it becomes necessary evolution of the discussions around clusters that incorporates considerations about such dimensions. Thus, this study aims at analyzing the occurrence of sustainable development practices, based on the triple bottom line model in a cluster. Therefore, it was chosen as empirical field study of a cluster of mobile, located in the municipality of Marco, in the state of Ceará. Your choice for this work was due both to the characteristics of this type of activity, which for depend on the extraction and use of natural resour- 
ces, especially timber, has a great relationship with issues of environmental sustainability, as for the recognition of the strong economic performance of the cluster of Marco, which caused the city to be recognized as one of the largest furniture centers in the North and Northeast. We sought to identify economic (profit), social (people) and environmental (planet) statements, as well as verify the occurrence of synergy in the relationship cluster and sustainable development. In the literature review, Topics were built on the theoretical approach of clusters, the role of the political entrepreneur or collective entrepreneur and sustainable development and the triple bottom line model. The methodology was based on a qualitative approach, whose techniques were semi structured interviews, observation and documentary corpus. Were intentionally and for accessibility chosen six entrepreneurs. It can be concluded that, based on the triple bottom line model, some characteristics of sustainable development are present, especially related to environmental (planet) and economic (profit). The social dimension (people) still need to be improved, which could happen by the influence of synergist or political entrepreneur. In short, this study has been to contribute to the understanding of the relationships between the various dimensions of sustainable development and practices observed in the context of clusters.

\section{KEYWORDS}

Sustainable development; Cluster; Triple bottom line; Synergistic relationship; Pole furniture.

\section{ARREGLO PRODUCTIVO LOCAL Y EL DESARROLLO SOSTENIBLE: UNA RELACIÓN SINÉRGICA EN LA CIUDAD DE MARCO (CE)}

\section{RESUMEN}

Con la evolución del concepto de desarrollo, mediante el fortalecimiento del paradigma de la sostenibilidad, se hace necesaria una evolución de los debates en torno de los Arreglos Productivos Locales (APLs), incorporando pesa alrededor de tales dimensiones. Así, este estudio tiene como objetivo analizar la incidencia de las prácticas de desarrollo sostenible, basado en el modelo triple bottom line, en un arreglo productivo local. Por lo tanto, se eligió como campo de estudio un APL de muebles, ubicado en la ciudad de Marco, en el estado de Ceará. Su elección 
para este trabajo fue debido tanto a las características de este tipo de actividad, que dependen de la extracción y el uso de los recursos naturales, especialmente de madera, tiene una gran relación con los temas de sostenibilidad ambiental, como el reconocimiento del buen desempeño económico del APL de Marco, lo que provocó que la ciudad sea reconocida como uno de los mayores centros de muebles en el Norte y Nordeste del país. Hemos tratado de identificar declaraciones económicos (profit), sociales (people) y ambiental (planet), así como verificar la existencia de sinergia en el relación arreglo productivo y desarrollo sostenible. Al revisar la literatura, se construyeron los temas en el enfoque teórico de arreglos productivos local, el papel del emprendedor político e o empresario colectivo y sobre el desarrollo sostenible y el modelo triple bottom line. La metodología se basa en un enfoque cualitativo y las técnicas fueron entrevistas semi estructuradas, observación y corpus documental. Fueron elegidos intencionalmente y accesibilidad seis empresarios. Se puede concluir que con base en el modelo triple bottom line, se presentan algunas características del desarrollo sostenible, principalmente relacionados con el medio ambiente (planet) y económica (profit). La dimensión social (people) todavía necesita ser mejorada, lo que podría ocurrir por la influencia de un sinergista o un empresario político. En resumen, este estudio contribuye a la comprensión de las relaciones entre las distintas dimensiones del desarrollo sostenible y las prácticas observadas en el contexto del APLs.

\section{PALABRAS CLAVE}

Desarrollo sostenible; Arreglo productivo local; Triple bottom line; Relación sinérgica; Industria del mueble.

\section{REFERÊNCIAS}

ALBAGLI, S. Informações e desenvolvimento sustentável: novas questões para o século XXI. Ciência da Informação, São Paulo, v. 24, n. I, p. I-9, I995.

ALMEIDA, F. O bom negócio da sustentabilidade. Rio de Janeiro: Nova Fronteira, 2002.

AMORIM, M. Clusters como estratégia de desenvolvimento industrial no Ceará. Fortaleza: Banco do Nordeste, I998.

ANDERSON, K.; BLACKHURST, R. The greening of world trade issues. London: Harvester Wheatscheaf, I992. BAGNASCO, A. Tre Italie. La problematica territoriale dello sviluppo italiano. Bologna: Il Mulino, I977. BAGNASCO, A. A teoria do desenvolvimento e o caso italiano. In: ARBIX, G.; ZILBOVICIUS, M.; ABRAMOVAY, R. (Orgs.). Razões e ficções do desenvolvimento. São Paulo: Unesp/Edusp, $200 \mathrm{I}$. BAGNASCO, A. Desenvolvimento regional, sociedade local e economia difusa. In: COCCO, G.; URANI, A.; GALVÃO, A. (Orgs.). Empresários e empregos nos novos territórios produtivos: o caso da Terceira Itália. 2. ed. Rio de Janeiro: DP\&A, 2002. 
- RAFAELLA ALVES M. ALVARENGA • FÁTIMA REGINA NEY MATOS・DIEGO DE QUEIROZ MACHADO • - MICHELLE DO CARMO SOBREIRA • LORENA BEZERRA DE SOUZA MATOS •

BAPTISTA, C. Distritos flexíveis e desenvolvimento endógeno: uma abordagem "marshalliana”, 2002. Disponível em: <http://geocities.com/statprof/distrit.html>. Acesso em: 20 jan. $20 \mathrm{or}$.

BARBOSA, G. S. O desafio do desenvolvimento sustentável. Revista Visões, Rio de Janeiro, v. I, n. 4, p. I-II, jan./jun. 2008.

BARQUERO, A. V. Desenvolvimento endógeno em tempos de globalização. Porto Alegre: Fundação de Economia e Estatística, 200I.

BECATTINI, G. Mercato e forze locali: il distretto industriali. Bologna: Il Mulino, I987.

BECATTINI, G. The Marshallian industrial district as a socio-economic notion. In: PYKE, F.; BECATTINI, G.; SENGENBERGER, W. (Ed.). Industrial districts and inter-firm coooperation in Italy. Geneve: International Institute for Labour Studies, ILO, I990.

BECKER, B. A Amazônia pós ECO-92. In: BURSZTYN, M. (Org.). Para pensar o desenvolvimento sustentável. São Paulo: Brasiliense, I993.

BERTALANFFY, L. Teoria geral dos sistemas. 3. ed. Petrópolis: Vozes, I977.

BOISIER, S. Y si el desarrollo fuese uma emergencia sistémica? Redes, v. 8, n. I, p. 4-42, 2003.

BRASIL. Ministério do Desenvolvimento, Indústria e Comércio Exterior. Plano de desenvolvimento do arranjo produtivo local de móveis do Marco Ceará. 2008. Disponível em: <http://www.desenvolvimento.gov.br/arquivos/dwnl_I247146779.pdf>. Acesso em: I7 jul. 2012.

BRUSCO, S. The idea of the industrial district: its genesis. In: PYKE, F.; BECATTINI, G.; SENGENBERGER, W. (Ed.). Industrial districts and inter-firm cooperation in Italy. Geneve: International Institute for Labour Studies, ILO, I990.

BRUSCO, S.; SABEL, C. Artisan production and economic growth, in the dynamics of labour market segmentation. London: Academic Press, I98I.

BRUYNE, P.; HERMAN, J.; SCHOUTHEETE, M. Dinâmica da pesquisa em ciências sociais - os pólos da prática metodológica. Rio de Janeiro: Francisco Alves, I977.

BUARQUE, S. Construindo o desenvolvimento local sustentável. Rio de Janeiro: Garamond, 2006.

CALLENS, I.; TYTECA, D. Methods: toward indicators of sustainable development for firms, a productive efficiency perspective. Ecological Economics, n. 28, p. 4I-53, I999.

CAMAGNI, R. Local milieu, uncertainty and innovation networks: towards a new dynamic theory of economic space. In: CAMAGNI, R. (Ed.). Innovation networks - spatial perspectives. London: Belhaven Press, I99I.

CARROL, A. Corporate social responsibility: evolution of a definitional construct. Business and Society, v. 8, p. 268-295, I999.

CASSIOLATO, J. E.; LASTRES, H. M. Inovação, globalização e as novas políticas de desenvolvimento industrial e tecnológico. In: CASSIOLATO, J. E.; LASTRES, H. M. (Ed.). Globalização e inovação localizada: experiências de sistemas locais no Mercosul. Brasília: Ibict/IEL, I999.

COCCO, G.; GALVÃO, A.; SILVA, M. Desenvolvimento local e espaço público na Terceira Itália: questões para a realidade brasileira. In: GALVÃO, A.; URANI, A.; COCCO, G. (Orgs.). Empresários e empregos nos novos territórios produtivos: o caso da Terceira Itália. Rio de Janeiro: DP\&A, I999. p. I3-32. COOKE, P. Regional innovation systems: an evolutionary approach. In: BARACZYK, H.; COOKE, P.; HEIDENREICH, R. (Ed.). Regional innovation systems. London: University of London Press, I996.

CORÓ, G. Distritos e sistemas de pequena empresa na transição. In: URANI, A.; COCCO, G.; GALVÃO, A. (Orgs.). Empresários e empregos nos novos territórios produtivos: o caso da Terceira Itália. Rio de Janeiro: DP\&A, I999. p. I47-I97. 
EDQUIST, C. (Ed.). Systems of innovation: technologies, institutions and organizations. London: Pinter, I997.

ELKINGTON, J. Sustentabilidade, canibais com garfo e faca. São Paulo: M. Books, 2012.

FILION, L.; LUC, D.; FORTIN, P. L'essaimage d'entreprises. Vers de nouvelles pratiques entrepreneuriales. Montreal: Les Éditions Transcontinental, 2003.

FREEMAN, C. Technology policy and economic performance: lessons from Japan. London: Pinter Publishers, I987.

FUÀ, G. L’industrializzazione nel Nord Est e nel Centro. Bologna: Il Mulino, I983.

FULLER, B. Synergetics: explorations in the geometry of thinking. New York: Collier Books, I982.

GALLICCHIO, E. El desarollo local: como combinar gobernabilidad, desarollo económico y capital social en el território. In: ROFFMAN, A.; VILLAR, A. (Orgs.). Desarollo local: una revisión critica del debate. Buenos Aires: Espacil Editorial, 2006. p. 59-74.

GALLOPÍN, G. Prospectiva ecológica de América Latina y revolución tecnológica. In: CONGRESSO LATINOAMERICANO SOBRE POLITICAS CIENTIFICAS Y TECNOLOGICAS, 3., I988, São José, Costa Rica. Anais... São José: Ministério de Indústria, Comércio y Turismo, I988.

GLAESER, B.; UYASULU, V. The obsolescence of ecodevelopment? In: GLAESER, B. (Org.). Ecodevelopment: concepts, projects, strategies. Oxford: Pergamon, I984.

GUDYNAS, E. Etica, ambiente y desarrollo em Latinoamerica. Apuntes de ecologia. Uruguai: Cipfe, I989.

HAESBAERT, R. Territórios alternativos. São Paulo: Contexto, 2002.

HART, S. Beyond greening: strategies for a sustainable world. Harvard Business Review, v. 75, p. 66-76, I997.

INSTITUTO BRASILEIRO DE GEOGRAFIA E ESTATÍSTICA. Contagem da população 1996. I996. Disponível em: <http://www.ibge.gov.br/home>. Acesso em: ago. 20 I2.

INSTITUTO BRASILEIRO DE GEOGRAFIA E ESTATÍSTICA. Censo demográfico 2012. 2010. Disponível em: <http://www.ibge.gov.br/home>. Acesso em: ago. 2012.

INSTITUTO DE PESQUISA E ESTRATÉGIA ECONÔMICA DO CEARÁ. A evolução do PIB dos municípios cearenses no período 2002-2010. 20I2. Disponível em: <http://www.ipece.ce.gov.br/publicacoes/ipece-informe/Ipece_Informe_49_20_dezembro_20I2.pdf>. Acesso em: Io jan. 2012.

INTERNATIONAL UNION FOR CONSERVATION OF NATURE AND NATURAL RESOURCES (IUCN). World conservation strategy: Living resource conservation for sustainable development. Gland: IUCN, I980.

JAMES, P. et al. Work of the future. Sydney: Allen \& Unwin, I997.

KELLER, P. Cluster, distritos industriais e cooperação interfirmas: uma revisão da literatura. 2008. Disponível em: <http://www.iceg.pucminas.br/espaco/revista/ı6Clusters \%20,\%2odistritos\%20 industriais\%2oe\%2ocoopera\%C3\%A7\%C3\%A30\%2oin_terfir.pdf>. Acesso em: 26 jan. 2012.

KLIKSBERG, B. Repensando el Estado para el desarrollo social: más allá de convencionalismos. Buenos Aires: Centro de Documentación en Políticas Sociales, I998.

KRUGMAN, P. Development, geography and economic theory. Cambridge: MIT Press, I995.

LASTRES, H.; CASSIOLATO, J. Glossário de arranjos e sistemas produtivos e inovativos locais. Rio de Janeiro, 2005. Disponível em: <http://redesist.ie.ufrj.br/glossario.php>. Acesso em: 22 fev. 2012. LIMA, F. Histórias de sucesso, indústria, madeira e móveis. Brasília: Sebrae, 2007. 
- RAFAELLA ALVES M. ALVARENGA • FÁTIMA REGINA NEY MATOS • DIEGO DE QUEIROZ MACHADO • - MICHELLE DO CARMO SOBREIRA • LORENA BEZERRA DE SOUZA MATOS •

LUNDVAL, B. A. User-producer relationships and national systems of innovation. In: LUNDVAL, B. A. (Ed.). National systems of innovation: Towards a theory of innovation and interactive learning. London: Pinter, I992.

MARKUSEN, A. Sticky places in slippery space: a typology of industrial districts. Economic Geography, v. 72, n. 3, p. 293-313, July I996.

MARSHALL, A. Princípios de economia. 2. ed. São Paulo: Nova Cultural, I985.

MARTINELLI, D.; JOYAL, A. Desenvolvimento local e o papel das pequenas e médias empresas. Barueri: Manole, 2004 .

MCNAUGHTON, R. Industrial districts and social capital. In: GREEN, M.; MCNAUGHTON, R. (Ed.). Industrial networks and proximity. Aldeshort: Ashgate, 2000.

MERRIAM, S. Qualitative research and case study applications in education. San Francisco: Jossey-Bass, I998.

MINAYO, M. O desafio do conhecimento - pesquisa qualitativa em saúde. Io. ed. São Paulo: Hucitec, 2007.

NASCIMENTO, L.; LEMOS, A.; MELLO, M. Gestão socioambiental estratégica. Porto Alegre: Bookman, 2008.

NEGRI, A. O empresário político. In: GALVÃO, A.; URANI, A.; COCCO, G. (Orgs.). Empresários e empregos nos novos territórios produtivos: o caso da Terceira Itália. Rio de Janeiro: DP\&A, I999.

PATTON, M. Qualitative research and evaluation methods. 3. ed. Thousand Oaks: Sage, 2002.

PINTO, A. Notas sobre estilos de desarrollo en America Latina. Revista de la Cepal, Santiago, n. 96, p. 73-93, 2008.

PIORE, M.; SABEL, C. The second industrial divide: possibilities for prosperity. New York: Basic Books, I984.

PORTER, M. Competição - estratégias competitivas essenciais. I3. ed. Rio de Janeiro: Elsevier, I999. PROGRAMA DAS NAÇÕES UNIDAS PARA O DESENVOLVIMENTO. IDH Municípios 2010. 20I2. Disponível em: <www.pnud.org.br>. Acesso em: ago. 2012.

PIKE, F.; SENGENBERGER, W. (Ed.). Industrial districts and economic regeneration. Geneva: International Labour Studies, I992.

QUIVY, R.; CAMPENHOUDT, L. Manual de investigação em ciências sociais - trajectos. Lisboa: Gradiva, 2008.

SACHS, I. Poblacion, tecnologia, recursos naturales y médio ambiente. Boletín Económico de America Latina, v. I8, n. I-2, p. II7-I29, I973.

SACHS, I. Ecodesenvolvimento: crescer sem destruir. São Paulo: Vértice, I986.

SACHS, I. Caminhos para o desenvolvimento sustentável. Rio de Janeiro: Garamond, 2002.

SACHS, I. Desenvolvimento includente, sustentável, sustentado. Rio de Janeiro: Garamond, 2008.

SANTOS, M. A aceleração contemporânea: tempo mundo e espaço mundo. In: SANTOS, M. et al. (Org.). O novo mapa do mundo: fim de século e globalização. São Paulo: Hucitec, I993. p. I5-22.

SANTOS, M. Por uma outra globalização: do pensamento único à consciência universal. 2. ed. São Paulo: Record, 2000.

SCHMITZ, H. Global competition and local co-operation: success and failure in the Sinos valley, Brazil. World Development, v. 27, n. 9, p. 1627-1650, I999.

SCIPIÃO, T. Pequenas e médias empresas puxando o desenvolvimento: a formação do cluster moveleiro de Marco e Bela Cruz. 2000. 64 f. Trabalho de Conclusão de Curso (Graduação em Economia)Universidade Federal do Ceará, Fortaleza, 2000. 
SCOTT, A. The geographic foundations of industrial performance. In: CHANDLER JR., A.; HAGSTROM, P.; SOLVELL, O. (Ed.). The dynamic firm - the role of technology, organization and regions. Oxford: Oxford University Press, ig88.

SEN, A. Desenvolvimento como liberdade. São Paulo: Companhia das Letras, 2000.

SENGENBERGER, W.; PIKE, F. Distritos industriais e recuperação econômica local: questões de pesquisa e de política. In: COCCO, G.; URANI, A.; GALVÃO, A. (Orgs.). Empresários e empregos nos novos territórios produtivos - o caso da Terceira Itália. Rio de Janeiro: DP\&A, I999.

SPINK, P. Pesquisa de campo em psicologia social: uma perspectiva pós-construcionista. Psicologia \& Sociedade, v. I5, n. 2, p. I8-42, 2003.

STEGER, U. The business of sustainability: building industry cases for corporate sustainability. Basingstoke: Palgrave Macmillan, 2004.

STORPER, M. Regional technology coalitions: an essential dimension of national technology policy. Research Policy, v. 24, n. 5, p. 895-9II, I995.

SUNKEL, O. Introduccion. La interaccion entre lós estilos de desarrollo y el meio ambiente em America Latina. Siglo XX. Estilos de Desarrollo y Médio Ambiente en la America Latina, v. 36, n. I, p. I7-53, I980.

TENDLER, J. Good government in the tropics. London: The Johns Hopkings University Press, I997. VEIGA, J. da. Meio ambiente e desenvolvimento. São Paulo: Senac, 2006.

WINN, M.; KIRCHGEORG, M. The siesta is over: a rude awakening from sustainability myopia. In: SHARMA, S.; ARAGÓN-CORREA, J. A. (Ed.). Corporate environmental strategy and competitive advantage. North Hampton: Edward Edgar, 2005 p. 232-258.

WOLFE, M. Desarrollo: imágenes, concepciones, critérios, agentes, opciones. Boletín Económico de America Latina, v. I8, n. I-2, p. I-I2, I973.

WORLD COMMISSION ON ENVIRONMENT AND DEVELOPMENT. Our common future. I987. Disponível em: <http://www.un-documents.net/wced-ocf.htm>. Acesso em: ago. 2012. YIN, R. Estudo de caso: planejamento e métodos. 3. ed. Porto Alegre: Bookman, 2005. 